\title{
The Rising U.S. Trade Deficit With China And Why It Won't Go Away
}

James W. Gabberty, (Email: JGabberty@Pace.edu), Pace University

\begin{abstract}
During the latter half of 1998, Laura D'Andrea Tyson, former chairwoman of the President's Council of Economic Advisers and economics professor at Berkeley, wrote a highly-publicized commentary that questioned whether China would replace Japan as the antagonist in America's trade deficit woes. ${ }^{I}$ She stated "As the U.S. trade deficit with China continues to increase, concerns mount that China will soon replace Japan as America's major trade headache. Such concerns are fed by an image of China as another Japan - a country pursuing a mercantilist development strategy based on closed markets, an undervalued currency, and a structural trade surplus." Highlighting Japan's closed markets, undervalued currency, and perennial trade surplus, Tyson's monograph calls into question whether China's trade practices will parallel the manic logic of mercantilism so vehemently practiced by Japan. This paper examines the burgeoning supremacy characteristic of modern China's export-oriented trade program and provides useful, suggestive commentary on how U.S. trade policy with China should be handled, drawing conclusively from the Japanese experience. Finally, the causes underpinning the rising U.S. import/export ratio with China will be investigated.
\end{abstract}

\section{INTRODUCTION}

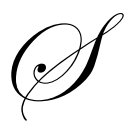

ix years have passed since Tyson's article assuaged fears of huge Chinese trade surpluses. Since the appearance of Tyson's article, China not only passed Japan as having the largest trade surplus with the U.S, it is setting all-time high records that are unlikely to subside anytime soon.

Assuredly, most Americans would be readily able to explain the normative lop-sided pattern of trade that culminates in the highly publicized trade imbalance. From automobiles to consumer electronics to construction and medical systems equipment for example, Japan's export-oriented mentality has resulted in a substantial and envied penetration into the U.S. market. Threaded throughout any discussion about their achievements is the underlying theme that we buy an overwhelming amount of Japanese exports while the Japanese shun U.S. manufactured products.

Likewise, from a Chinese trade deficit perspective, the current view held by most Americans remains much more misunderstood, not because of a lack of understanding of basic international trade theory, but rather from a lack of readily available data. For example, Americans are reminded - indeed bombarded - on a daily basis with cues concerning the pervasiveness of Japanese products in their everyday lives. Ubiquitous Japanese brands such as Sony, Canon, Mitsubishi, Toyota, Hitachi and others have become commonplace in every aspect of American culture - from consumer electronics and medical systems equipment to office machinery and defense-related technologies. Yet when asked to name a single Chinese brand, U.S. consumers remain confounded, even though the components inside many of these familiar Japanese manufactures are be produced - at increasing rates - by Chinese firms. It is then no wonder that most Americans are astonished to learn that their nation's trade deficit with Japan was eclipsed several years ago by that with China and that Chinese penetration into the American culture continues to grow at an astonishing rate.

Concurrent with increased import volumes is the apparent willingness among U.S. citizens to be burdened with higher debt levels sustained by ever-increasing foreign debt obligations to the tune of roughly $\$ 2$ billion dollars 
per day. Consider that in 1992, the U.S. trade gap totaled $\$ 36$ billion for the entire year. Halfway through 2000, it reached $\$ 30$ billion per month, and by January 2004 it reached in excess of $\$ 43$ billion per month - a shortfall that must be mitigated by selling ever more Treasury bonds to foreign governments and investors (see figure I). ${ }^{2}$

With each passing year, both the numerators and denominators used to calculate import/export ratios for this trading triad (Chinese - Japanese - U.S.) grow larger in size and the importance of ratios like these and others has no universally-agreed historical precedent that prescribes the normalized range of values or otherwise absolute perfect balance between the components that should exist.

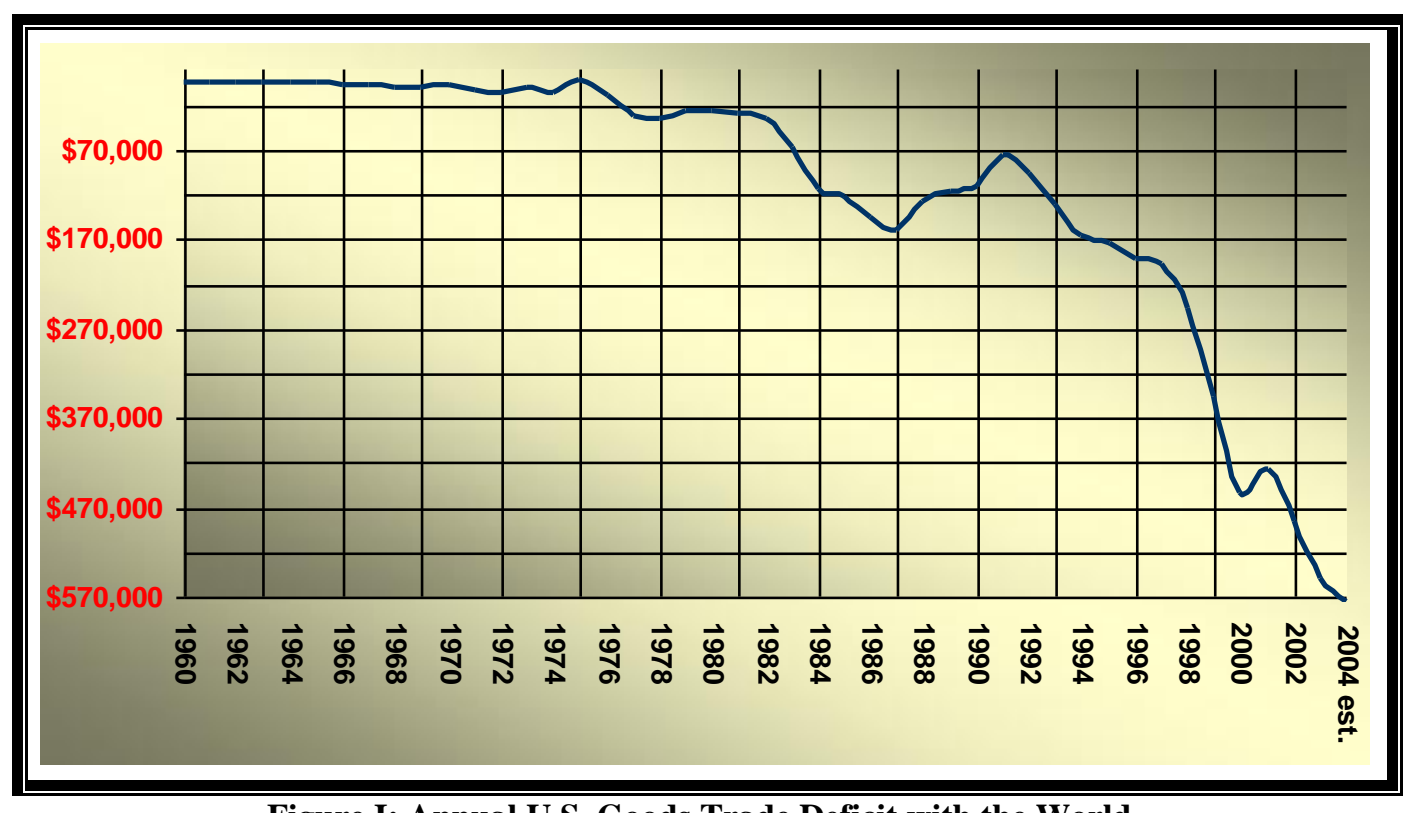

Figure I: Annual U.S. Goods Trade Deficit with the World

(US\$ Millions)

Source: U.S. Census Bureau, http://www.census.gov/foreigntrade/statistics/historical/gands.pdf

This paper will examine the issues surrounding the growing Chinese trade surplus with the U.S. and provide several prescriptive measures that need to be made to allay continuance of this engorging figure and counter the negative aspects associated with the long-term affects of the current account imbalance. Correspondingly, the following cause-and-effect questions will be examined: (1) Is China following in Japan's footsteps? (2) Is the trade imbalance with China harmful to the U.S.? (3) What policies, if any, should be enacted to forestall future damage done by trade with China and Japan to the U.S. economy?

\section{IS CHINA FOLLOWING JAPAN'S MERCANTILIST PRACTICES?}

According to the technological gap model, many of the exports of industrial nations are based on the introduction of new products and new production processes. These processes give the nation a temporary monopoly until other nations copy the technology and undersell the nation that introduced the newer technology. In the meantime, the technological leader may have introduced still newer products and newer production processes. A generalization and extension of the technological gap model is Vernon's product cycle model (Vernon, 1966). According to this model, the introduction of a new product usually requires highly skilled labor in the production process. As the product matures and acquires mass acceptance, its production becomes standardized, requiring only unskilled labor. The comparative advantage then shifts from the nation that introduced the product to the nation with the cheaper labor. Many of the products of the U.S. (often the technological leader) involve the continuous introduction of new products. For example, immediately after World War II, the U.S. dominated the world market 
for radios based in vacuum tubes developed in the U.S. A few years later, Japan understood and copied the technology for export to the swelling U.S. market, leveraging their lower wage costs. The U.S. recaptured the technological leadership and market with the development of transistors. But again, in a few years, Japan gained the necessary knowledge to copy the technology and outsell the U.S. in markets abroad. The U.S. continued innovating, introducing the printed circuit and reacquired its ability to successfully compete with Japan. Today, the most concentrated (i.e., powerful and fast) microprocessors available are produced by the world's premiere microprocessor firms namely, IBM (mainframes), Intel (workstations), and Motorola (cellular telephones), all multinationals based in the U.S. Japan, on the other hand, produces slightly less sophisticated microprocessors for (mostly) Japanese-branded electronics with components from firms such as NEC, Hitachi, and Matsushita. Now, however, China has become 'Japan' in the context of the above example, producing even less sophisticated products for Japanese consumer electronics goods.

The theory of foreign direct investment has received much scrutiny by international trade theorists because of the massive inflows of FDI into China. Beginning around 1990 and reaching approximately $\$ 54$ billion for 2003 (second only to the United States), inbound FDI for China is skyrocketing, driven by global multinationals string toward competitive advantage made possible by setting up production centers in mainland China. The rationale that motivates a firm's entry into international operations may be classified into three categories - (1) firms as seekers (of resources, factor advantage, knowledge, security, and markets), (2) firms as exploiters of imperfections (in access, factor mobility, and management), and (3) firms as internalizers (keeping secret their operation processes) (Czinkota, Ronkainen, \& Moffet 2000; Buckley \& Casson 1998).

Lastly, though other theories prevail, the eclectic theory \& OLI paradigm of foreign direct investment substantiates the frenzied pace of foreign firms rushing into China to capitalize on the opportunities awaiting foreign firms seeking (1) ownership advantages, (2) locational advantages, and (3) internalization advantages (Dunning, 1997). Capitalizing on the associated economic advantages of the paradigm, the benefits arising from the spatial distribution of factor endowments, costs and productivity of inputs, size of the [potential] market and rising income levels, and international transportation and communication costs serve as significant enticements for multinational corporations moving production centers to China (Gabberty and Calloway, 2004).

To determine if China is likely following in the footsteps of Japan by mimicking the mercantilist policies of Japan, it is useful to first investigate the relative trade supremacy gained by China is recent years. Figure II displays historical ratios spanning 18 years of the values of U.S. imports divided by the values of U.S. exports for trading partners China and Japan, respectively. For the simple purposes of illustration, consider that the two nations have identical balance of trade surplus figures with the United States (for 2003, Japan's exceeded $\$ 170$ billion and China's exceeded \$180). Also assume that for any given year this figure is $\$ 60$ billion (as it was in 1994 with Japan).

First, even though the net trade deficit that the U.S. suffers from these two countries is identical, the implications for each trading partner are starkly different. In the case of China, it can be hypothesized that the benefits for that nation's bilateral trade imbalance with the U.S. are vastly greater for itself than for Japan in terms of the sheer amount of U.S. dollars flowing into China, a developing nation with low but rising GDP per capita rates. In 1999, for example, Chinese exports to the U.S. accounted for roughly $22.5 \%$ of the nation's GDP figure for that year. In contrast, Japan's exports to the U.S. for that same period accounted for less than half of the Chinese figure, or only $10 \%$ of its GDP for the same year; for 2003 , that figure stood at $35 \%$ of GDP.

Secondly, in contrast to above, (and also in terms of the sums of U.S. FDI flowing to each of these economies), the benefit for Japan's continuous bilateral trade imbalance with the U.S. is vastly greater than that of China, since the total export value for Japan is $\$ 60$ billion greater than that of China (see Table I) Trade balances for past twenty years.

A third twist may be described in the difference of in terms of significance the trade ratio implies as to the technical maturation (or technological advancement) of each export producer continues to grow. For China, its newly acquired taste for exports to the U.S. is demonstrated by its skyrocketing import/export ratio demonstrated 
above by the trend line whose slope is radically steeper than that of Japan's. China is deriving colossal benefits in terms of earnings from exports to the U.S., modernization of its manufacturing facilities, adaptation of Western methods of production, and so forth on account of its interaction (principally) with the U.S. and other economically and technologically advanced countries. Japan, a fully matured exporting juggernaut, does not necessarily have as much dependence on continued Western interaction to improve its exporting prowess. These benefits, which are intangible but quantifiable forms of wealth accumulation, in the case of China may exceed (perhaps by several times) the actual GDP of China as measured in financial terms by the PRC and perhaps The World Bank, UN, or OECD. For Japan, though while significant, these intangible benefits may not account for as high a value to the Japanese manufacturing sector owing to their long-standing trade surpluses with the U.S.

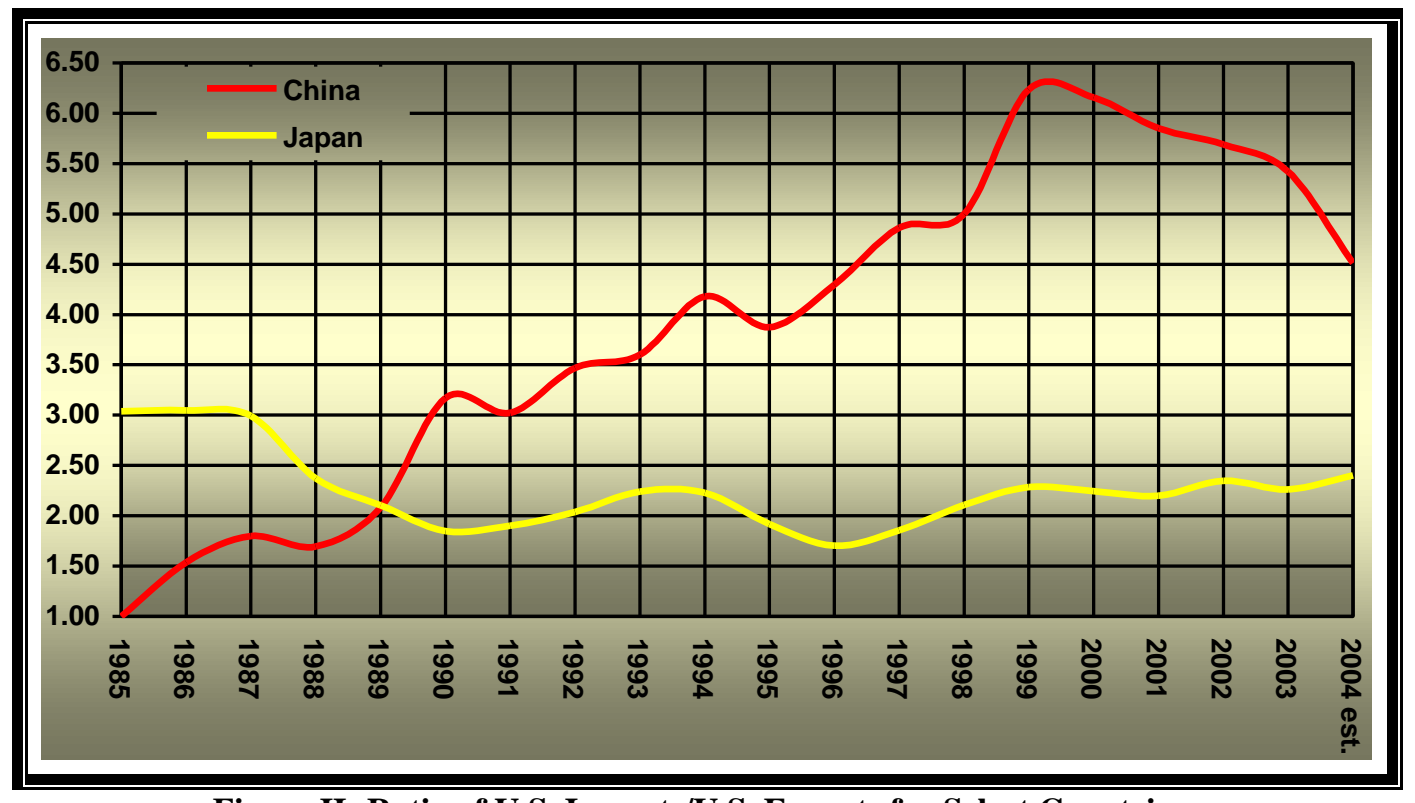

Figure II: Ratio of U.S. Imports/U.S. Exports for Select Countries

Source: U.S. Census Bureau, http://www.census.gov/foreign-trade/balancel \& http://www.bea.doc.gov/bea/newsrel/trad1302.pdf; Table 1328 from Statistical Abstract of the US 2000; Tables BX.GSR.MRCH.CD \& BM.GSR.MRCH.CD, World Development Indicators 2002, IBRD

Fourthly, in terms of overall export activity, China's exports to the U.S. in 1999 accounted for approximately $28 \%$ of its total export value while the export value for Japan is represented only $6 \%$ for the same year. Clearly, China's dependency on U.S. consumers is more significant (as a percentage of total export activity) than is Japan's dependency on its exports to the U.S., even though the dollar value for total Japanese exports to the U.S. exceeded Chinese exports to the U.S. for that year.

The booming Japanese economy from the 1960s through the mid-1980s was one of the most thoroughly studied and admired phenomena of modern economics. From steel to automobiles, consumer electronics to watches, Japanese companies easily overran their U.S. and (recently) European competitors. Western scholars praised Tokyo's careful economic planning and the focus of Japan's keiretsu - massive, interlocked networks of companies such as Mitsui, Mitsubishi, Matsushita, and Sumitomo - on building long-term competitive advantages. Other analysts attributed Japan's economic momentum to its workers' selfless dedication to improving productivity and to the extraordinarily high savings rates of its consumers. The fortunes of these economies, of course, have now reversed. America during the latter part of the 1990s, owing to a marvelous upsurge of confidence in its equity markets, experienced the longest unbroken economic expansion in its history, and Japan, by contrast, has been mired for more than a decade in stagnation that appears to have no end. It may be hypothesized that China is indeed following mercantilist Japan toward economic development and that China is for the world what Japan once was for 
the United States - a source for cheap manufactures. The products the U.S. once imported from Japan - such as computer components, consumer electronics, toys (both electromechanical and non-electromechanical), 'white' consumer goods like refrigerators, washers, and dryers, are now being supplied to the U.S. directly from China.

\section{THE GOVERNMENT-SPONSORED EXPORT DEPENDENCY OF CHINA}

Since 1979, China has been engaged in an effort to reform its economy. The Chinese leadership has adopted a pragmatic perspective on many political and socioeconomic problems, and has sharply reduced the role of ideology in economic policy. Political and social stability, economic productivity, and public welfare are considered paramount. In these years, the government has emphasized raising personal income and consumption and introducing new management systems to help increase productivity. The government also has focused on foreign trade as a major vehicle for economic growth.

Underpinning the world's astonishment toward the country is the rapid advance in China's foreign trade. Indeed, the level of foreign trade has climbed more quickly than GDP. This has led to a jump in the overall standard of living, as improvements in diets, clothing, housing, transportation and telecommunications, as well as greater access to consumer goods among both urban and rural residents. However, what impresses the world most is the rapid advance in China's foreign trade. Since 1978 the level of foreign trade has climbed more quickly than GNP. This, in turn, has led to a jump by a factor of three in China's share in international merchandise trade.

Figure III illustrates the percentage of Chinese exports that are consumed by the U.S. and the reciprocal percentage of U.S. exports consumed by the China. Although Chinese exports to the U.S. have more than trebled to the $50 \%$ level, U.S. exports to China remain lethargic at $2 \%$, or 25 times less than that of China!

Figure IV illustrates the percentage of total Chinese imports that come from the U.S. and the percentage of U.S. imports that come from China. Note that in the short span of approximately 15 years, China has achieved the dramatic percentage share in excess of ten percent - indicative of the growing dependency that China has on the U.S.

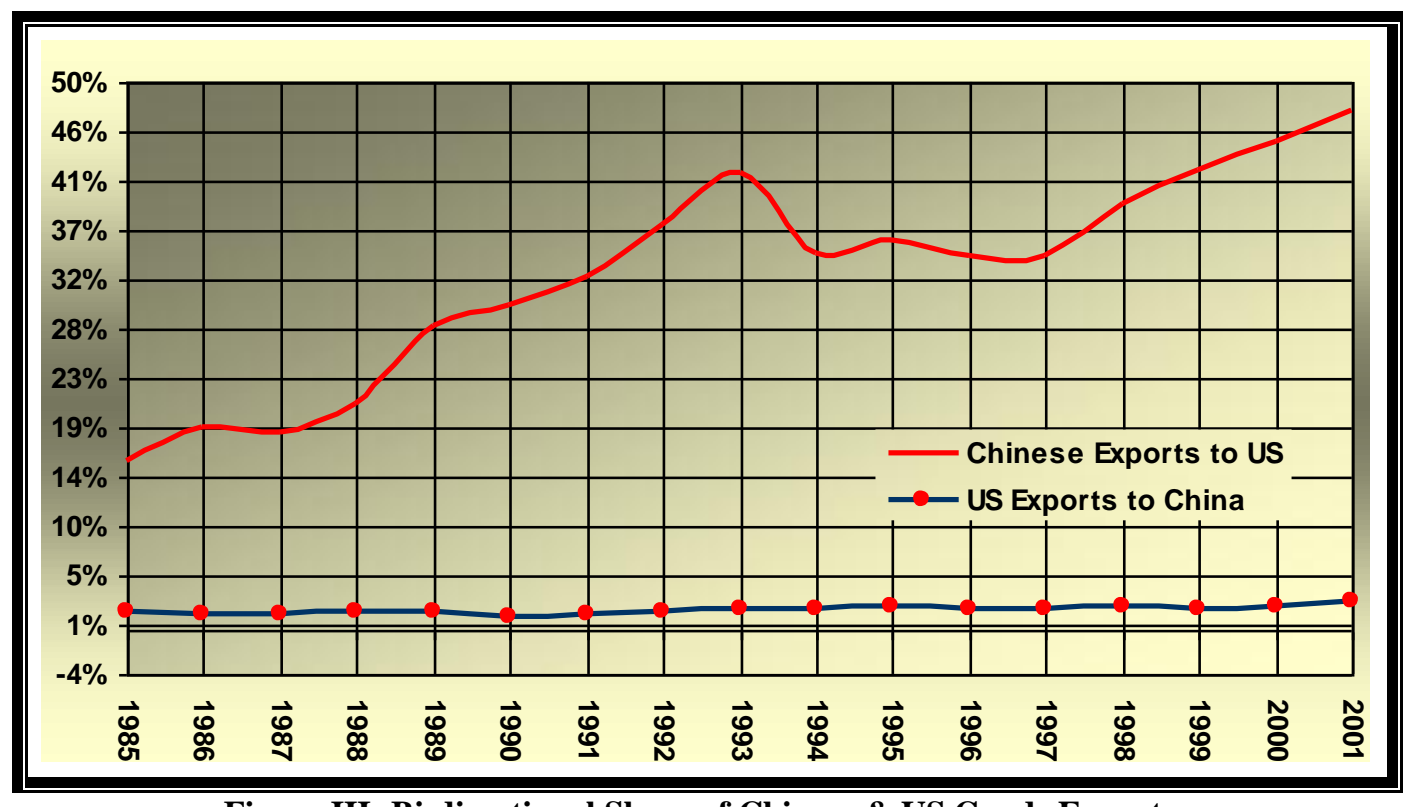

Figure III: Bi-directional Share of Chinese \& US Goods Exports

Source: U.S. Census Bureau, http://www.census.gov/foreign-trade/balancel \&

http://www.bea.doc.gov/bea/newsrel/trad1302.pdf; Table 1328 from Statistical Abstract of the US 2000;

Tables BX.GSR.MRCH.CD \& BM.GSR.MRCH.CD, World Development Indicators 2002, IBRD 


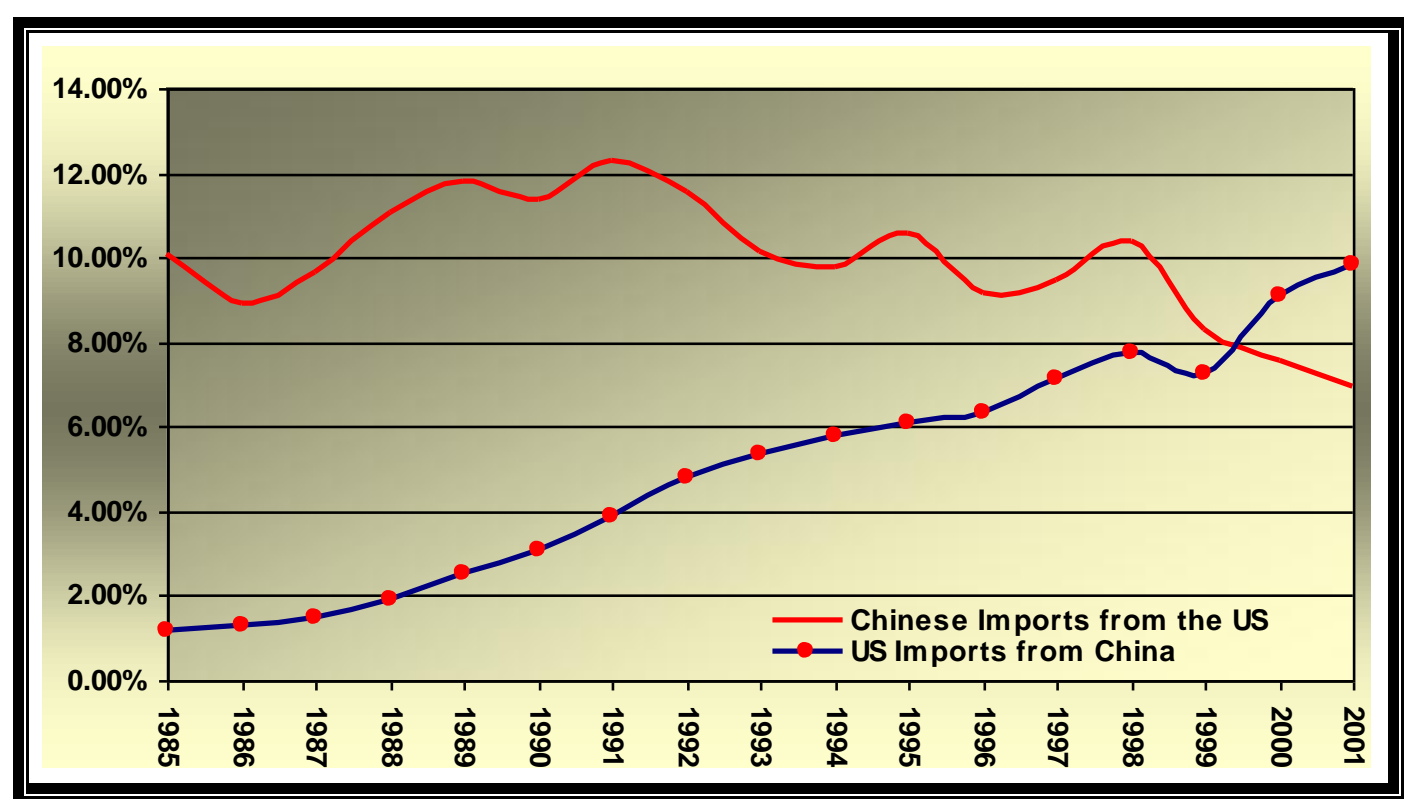

Figure IV: Bi-Directional Share of Chinese \& US Goods Imports

Source: Same as figure III

China's dependency on exports has taken on new meaning by a developing country seeking to enter the world economy. Figure $V$ illustrates the phenomenal rate of growth that exports have exhibited as compared to GDP growth. China is taking steps to decentralize its foreign trading system and integrate itself into the world trading system. In November 1991, China joined the Asia Pacific Economic Cooperation (APEC) group, which promotes free trade and cooperation in the economic, trade, investment, and technology spheres. China served as APEC chair in 2001, and Shanghai hosted the annual APEC leaders meeting in October.

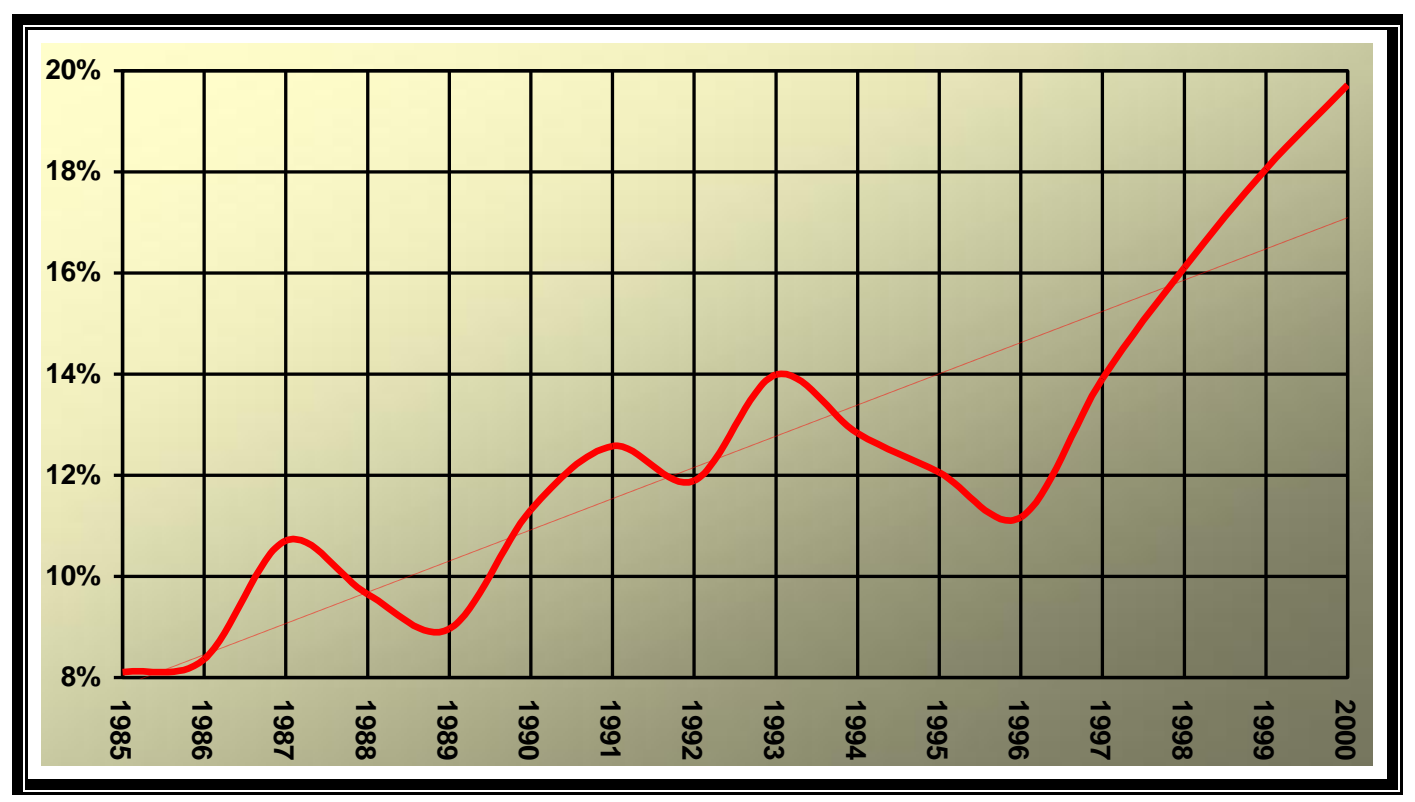

Figure V: Export Dependency of China

(Ratio of the Value of Exports of Goods, Services and Income / GDP)

Source: Tables NE.EXP.GNFS.CD \& NY.GDP.MKTP.CD, World Development Indicators 2002, IBRD 
China formally joined the WTO in December 2001. Accession marks the end of a 16 year long cycle of negotiations. As part of this far-reaching trade liberalization agreement, China agreed to lower tariffs and to abolish market impediments after it joins the WTO. Chinese and foreign businessmen, for example, will gain the right to import and export on their own, and to sell their products without going through a government middleman. Average tariff rates on key U.S. agricultural exports will drop from $31 \%$ to $14 \%$ in 2004 and on industrial products from $25 \%$ to $9 \%$ by 2005 . The agreement also opens up new opportunities for U.S. providers of services like banking, insurance, and telecommunications; this productive capacity expansion will serve China by increasing nation's capability to export.

\section{MACROECONOMIC DISTINCTIONS BETWEEN CHINA, JAPAN, AND THE US}

The economic differences between the nations comprising trading triad that is formed by China, Japan and the U.S. are stark. The U.S., in particular, strives to be as close to possible to a free market economy, protecting only a limited number of industries such as (recently, though temporarily) steel and (historically) textiles. Its domestic economy is structured in such as a way as to provide the American consumer with the highest quality products that producers of goods and services can deliver, irrespective of their national origin (although certain political restrictions cause exports from rogue nations such as Cuba, Iraq, Syria, Libya, and Iran to be severely constrained). In the U.S., the deliberate intent by early business practices and methods that ensured that the common worker would be entitled to sharing in the goods that they labor to produce is unique and best exemplified en mass by Henry Ford, who believed that workers ought to have the right (and ability) to purchase inexpensive and dependable automobiles for the workers whose toils made possible the automotive revolution that took place in the U.S. in the early 1900s.

Meanwhile, Japan best exemplifies a managed economy, cautiously (some say too slowly) approaching a more open market to imports. As stated by Eisuke Sakakibara, Vice-Minster of Finance of Japan from 1997 to 1999 - "One sector of the Japanese economy [the] exporting sub-sector, which is highly competitive, consisting of Toyota's and Sony's, and the other is a domestic manufacturing and domestic service industry [is] uncompetitive. You know, we have a market-oriented capitalistic system in the one hand and a very socialistic eqalitarian sought of sector on the other hand." In Japan, the great exporter, domestic industries are protected. At the very heart of the world's second largest economy lay a contradiction: how can a nation only opt for free markets with only a one-way (i.e., export-driven) mentality while not allowing imports into the nation which would raise the standard of living for its inhabitants? The inefficiencies resulting from their mercantilist bent are monumental and is precisely the reason cited most often as the root cause of that nation's stagnation.

Meanwhile, China is best characterized as a communist-controlled market economy only partially opening itself up (economically) to benefit itself through carefully run export programs, knowledge importation, and direct investment from abroad to fund its economic expansion.

\section{A COMPARATIVE VIEW CHINESE AND JAPANESE BUSINESS PRACTICES}

Although China and Japan are distinct and separate nations, the similarities and differences between their shared Confucian-driven roots pervades the mindsets of many aspects of their international and domestic business activities. For example, both Chinese and Japanese firms mitigate risk by having acquired substantial "organizational capital" - that is, business relationships that are dependent on family ties, trust, reputation, and repeated business dealings. These relationships allow firms to overcome many unexpected business downturns by leveraging money, contracts, and other cost-sharing measures from firms within their sphere of influence.

Additionally, Chinese and Japanese firms are able to raise money informally from within their networks of family ties and acquaintances, without having to go to a bank and show collateral for the loans or demonstrate to the equity markets a healthy and stable balance sheet.

Firms in Japan react to external market uncertainty by forming internal networks to take control over their suppliers and distribution systems. Thus Japan's keiretsu has established vertical ties with small-scale domestic 
producers and horizontal ties with one another. This strategy brings a wide range of transactions into a more controllable, closed system, reducing companies' exposure to the risks of opportunism and fluctuations in transaction prices in an unpredictable market. These large networks have evolved into industrial conglomerates (typically including a main bank) that allow intensive sharing of information and internal capital generation.

The Japanese business relationship strategy stands in sharp contrast to China's vast geographically dispersed business enterprises, where predatory or weak regional chiefs discourage industrial development. Operating without the institutional frameworks needed for arm's length exchanges, and fearing historic arbitrary and oppressive state intervention, many businesses in China have quite necessarily gravitated toward a distinctive trading style based on personal relationships known as "guanxi" - in other words, crony capitalism.

Chinese traders are loosely bound together by implicit contracts and depend on personal or communal sanctions, rather than the law, to enforce contract compliance. Guanxi is characterized by a personal relationship built on trust in an individual's ability to follow through on promises. This trust is acquired through repeated good performance and cannot be transferred from someone hired from the outside. The relationship also implies a responsibility to implement one's promises but does not include any formal obligation.

Networks built on such Guanxi therefore lack the formal ties needed to band together and be sold to an outside investor - indeed, any such loosely grouped network would have difficulty borrowing funds from outsiders in its own name. Murky ownership rights and the presence of unincorporated businesses acting with undefined liability mean that assets cannot be turned into capital. Instead, they can be traded only within narrow circles of acquaintances. The inability of many Chinese enterprises to enforce contracts with other enterprises prevents any one personal network from dominating the Chinese economy; consequently this hampers China's ability to evolve into more open systems of production. Unlike their Japanese counterparts, few Chinese businesses have transformed themselves into modern, complex corporations. Yet given the commercial environment they have been facing, those businesses would not have been able to prosper in the first place without these extensive and effective personal networks.

Although many critics of Chinese business are frustrated by the slow pace of institutional reform, both Asian business systems have valid reasons for not wanting to abandon the strategies that served them well in he past - at least not until underlying weaknesses in the business environment are corrected. Business transparency in China, for example, is dangerous in the present environment because firms that disclose profits can still be subject to arbitrary government audits and expropriations. And relying on internal transactions and closed production systems allows firms to be sure of the accuracy and timeliness of the financial and other information they receive, which might otherwise be in doubt.

In both Japan and China, moreover, new entrant companies have had difficulty breaking into the domestic market. In the 1960s and 1970s, efficient business management was rare and highly concentrated in specific regions, so government initiatives (mostly in Japan) and individuals (mostly in China) pushed capital toward the few capable firms. These companies were able to exploit economies of scale and scope, gaining significant advantage vis-à-vis new entrants and developing crucial links abroad. For smaller and less well established firms in the region to now flourish against such competition, they will need a free flow of capital, especially from external investors. But investors are unlikely to direct funds toward fresh and promising economic opportunities in the absence of a better legal framework, causing a conundrum for foreign investors, who demand accountability from owners to fully disclose relevant information, but the looser traditional business practices must concomitantly continue to make sense as long as contract enforcement remains enforcement.

The distinct differences between the corporate governances of China and Japan are similar by intent in that they make it difficult for foreigners to gain access to the local (domestic) market. Consequently, the careful judgmental skills necessary to form business relationships with firms inside these two formidable competitor nations are absolutely critical factors that burden Western companies vying to enter into such relationships. This causes delays and increases both risk and cost of establishing inter-firm ties and slows the short- and long-term planning process by corporations and in the economic branches of national administrations. By concentrating on these 
divergent national cultures, it is clear that emphasis on the development of mutual cooperation between the U.S. and both Japan and China for certain major product areas such as automobile production, low- to medium-technology parts assemblies, and high-end product manufactures such as telecommunications products and software production are likely to depend heavily on the orientation and comprehensiveness of corporate planning and government economic planning in the U.S. - Asian context over the next half decade. This being the case, it is likely that major inroads into either of these two Asian nations by U.S. firms seeking market reciprocity will face an upward climb; in contrast, each of these nations gets to enjoy the transparency features of U.S.-style corporate governance to enhance and grow their international marketing activities. This difference in business climates slows U.S. industrial policy initiatives designed to reverse a decline in the international competitiveness of American firms challenged in higher technology sectors by Japanese enterprises and lower technology sectors in China.

\section{IS CHINA FOLLOWING IN JAPAN'S FOOTSTEPS?}

Yes, but as a result of a different set of causal factors.

As an observer of the miraculous changes taking place in China, one cannot but perceive with wonder and amazement the degree of economic activity occurring in China, a nation who, within a brief period spanning some twenty years, is providing massive export volumes of mainly low- to medium- levels of technological sophistication, steadily advancing their export mix to include more technologically advanced products such as near state-of-the-art microprocessor "chip" level production and (increasingly) advanced software production, As was seen in the latter half of the 1990s, China was able to produce some of the components that make up the Microsoft Windows 95 software, arguably the world's most advanced, prominent, and technically mature software for operating personal computer platforms. Though the partnership with Microsoft quickly went astray on account of China's massive patent violation with its partner, China nonetheless gained access to incredible amounts of Western technology that cost billions of dollars to develop for little absolutely no money being exchange. Further, its pre-U.S. release and premature sales of Microsoft Windows 95 in 1995 (without Microsoft's permission) to its internal market helped millions of consumers gain access to the software free of charge and aided China's perception around the world as an untrustworthy partner on account of its repeated theft of technology.

In parallel to Japan's post World War II era of building up its infrastructure, China is committed to building its information and communications (ICT) infrastructure as a means of facilitating China's intent to join the world's economy and improve its own economic development. The fact that China is so committed to building out its telecommunications infrastructure not surprising, since by propagating personal computer access to the Internet for the masses, the ability to tie a nation of diverse sub-cultures more closely to Beijing (and its plans for economic expansion) becomes a reality. There are other reasons why China is deliberately focusing on building up its infrastructure so intently:

First, it is not to usher in a golden era of democracy. The Golden Projects allow it to modernize their information and telecommunications infrastructure so that they can provide the environment to compete in the global market and to attract multinational organizations with money that can be further invested into the Chinese economy (Gabberty, 2004). Prior to the launch of these Golden Projects initiatives, China was not noted for its ICT potential.

Second, this undertaking is another way of regaining control over the population while providing the illusion of liberty, providing a motivation rationale for the nation's workers. Even though many more Chinese citizens now have access to the Internet, they are forced to gain access through government-controlled sites that filter what they can and cannot access over the World Wide Web. There is an underground movement to provide uncensored Internet access, but it is periodically hampered through government intervention and harsh penalties.

Third, it has been estimated that by 2020 , China will be a superpower with the technological and economic might to easily compete with the United States and the European Union. A clear example of how this ties into the Golden Projects is the secret Chinese manned space program that plans to place a Chinese astronaut within the next five to ten years on the moon. The program, part of the Golden Projects, will further create jobs and innovation. 
When successful, the Chinese government will have acquired the same technology necessary to bolster its national defense, project its image as a nation that can be a competitor in the lucrative area of space transportation and a space ferrying nation, and put into place the technological incubators necessary to make it a large Information and Communications Technology (ICT) market. This is one of key reasons that much of China's human rights issues have been 'overlooked' by many nations. These nations want to have an opportunity to allow their nation's companies to gain access to valuable markets, talent, and cheap labor.

Fourth, another example of China's development in parallel to Japan is that when it successfully achieved the endeavors outlined in the points mentioned above, the nation's leaders can leverage these accomplishments by "proving" that socialism can function just as well as capitalism, even thrive. It can be likened to the Federal Works programs that FDR initiated during the 1930s to assist the United States in recovering from the Depression. China's economy was in turmoil until the 1970 s when the government began it innovative approach to enlarging the economy.

China's trade policies are modeled on Japan's, in other ways. Government ownership and control of the majority of economic resources, and an extensive network of government controls over banking, economic activity, trade and foreign exchange flows have combined to create the most unbalanced U.S. bilateral trading relationship. U.S. imports from China are five times as large as exports to that that country. Even at its most extreme, the U.S. Japan trade imbalance never exceeded a three-to-one ratio.

China's trade policies reflect an aggressive, state-led modernization effort that uses the pull of China's massive low-wage labor market to lure foreign direct investment from multinationals, while extracting the maximum amount of technology, jobs and exports from those relationships. China is rapidly advancing low technology products such as shoes and apparel into higher technology products such as [significant] aircraft components and parts, computers, motor vehicles and telecommunications equipment. Its magnificent ability to be successful in that regard is its recent passing of Japan as the world's greatest deficit trading nation with the U.S., as demonstrated in figure VI.

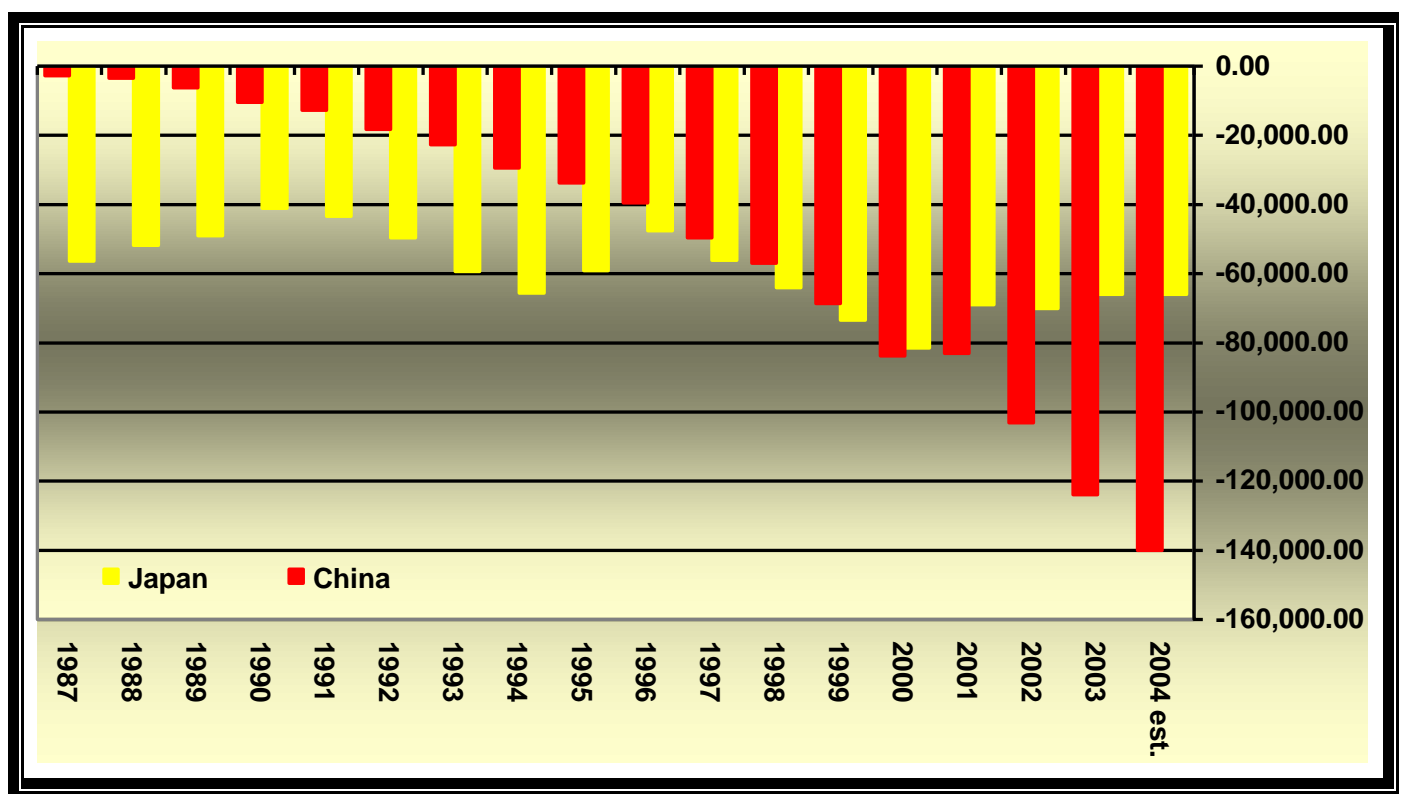

Figure VI: The U.S. Trade Deficit with Japan \& China

(\$US millions)

Source: U.S. Census Bureau, http://www.census.gov/foreign-trade/balancel \& http://www.bea.doc.gov/bea/newsrel/trad1302.pdf; Table 1328 from Statistical Abstract of the United States 2000; Tables BX.GSR.MRCH.CD\& BM.GSR.MRCH.CD, World Development Indicators 2002, IBRD 


\section{IF TRADE WITH CHINA IS HARMING THE U.S., WHY IS IT LIKELY TO CONTINUE?}

Despite its repeated patent violation witnessed during the 1990s, nations around the globe - including the U.S. - are not likely to stop and take pause of the consequences of the rapid economic development of China; rather, they are likely to accelerate their investments. One reason for the likely continued inflow of dollars into China is its ascension two years ago into the World Trade Organization, which, a case can be made, governs China's multilateral economic ties with trading nations through mechanisms established to litigate unfair behavior.

Second, the overwhelming push by free market economists and trade policy pundits in Washington, D.C., citing the apparent success (or non-manifestation of devastating blows to the U.S. economy) from the NAFTA initiative are likely to continue the push toward free trade. The mindset in Washington in recent years has been an acceleration of liberal economic philosophies such as open trade markets even though the typical outcome is open access only to the U.S. and protectionist counter-access provided by competitor nations. This is a troublesome trend that results in further swelling the trade deficit the U.S. carries with the world.

Third, unbalanced trade with China is likely to continue as U.S. companies seek to achieve lower costs of production for its products and these firms, of late, continue to favor China as a center of low-cost production. These market forces place heavy emphasis on the economic benefits derived from establishing trade relations and offshore production facilities in China in spite of the risks of fraud and patent violation as mitigating or countervailing reasons to seek close trade ties elsewhere.

Fourth, geopolitical factors - such as the impact of the vast trade imbalance between the China and the U.S. - do not enter into the mindset of U.S. corporate governance. The executives of huge U.S., conglomerates will, if it is in their firms' best interest (gauged by public performance measures such as stock price) will continue to ignore the myriad of concern surrounding the trade deficit controversy and instead myopically further focus on trade expansion with China to achieve cost reductions for the firm.

Fifth, the world's goods trade deficit with China - US\$ 84 billion in 2000 and US\$ 104 billion in 2002 and on target to reach \$US 120 billion in 2004 clearly reflects a country that intensely depends on the continuance of its U.S. trade deficit to maintain its rising current account surplus. Some of the factors that influence the U.S. trade deficit with China include:

Sixth, the strength of the U.S. economy is likely to be able to withstand additional ballooning of the trade deficit until such time as when the U.S. treasury is unable to make a payout to nations holding upwards of 25 percent of U.S. treasury bonds.

Seventh, there are no slowdowns in sight for U.S. consumer purchases of the inexpensive products being manufactured in China. The ability of that nation to supply, for example, dependable and basic consumer white goods such as ovens and refrigerators have allowed China to gain 25 percent of the market share for this industry.

Eighth, a shift of low-end assembly industries to China from the newly industrialized economies (NIEs) in Asia is continuing unabatedly. China has increasingly become the last link in a long chain of value-added production.

\section{CONCLUSION}

In the early decades of the 21 st century, many different social, economic and technological changes in the United States and around the world will affect the U.S. economy. The population of the United States will become older and more racially and ethnically diverse. The world population is expected to continue to grow at a rapid rate, while the U.S. population will likely grow much more slowly while Japan's contracts. World trade will almost certainly continue to expand rapidly if current trade policies and rates of economic growth are maintained, which in turn will make competition in the production of many goods and services increasingly global in scope. Technological progress is likely to continue at least at current rates, and perhaps faster. 
Although the U.S. economy will likely remain the world's largest national economy for the next several years, it is far less certain that U.S. households will continue to enjoy the highest average standard of living among industrialized nations. A number of other nations have rapidly caught up to U.S. levels of income and per capita output over the last five decades of the 20th century. They did this partly by adopting technologies and business practices that were first developed in the United States, or by developing their own technological and managerial innovations. But in large part, these nations are quickly catching up with the United States because of their higher rates of savings and investment, and in some cases, because of their stronger systems for elementary and secondary education and for training of workers.

No nation has ever had the rich supply of resources to face the future that the U.S. economy has as it enters the 21 st century. Despite (or in spite of) this, U.S. consumers continue to opt for imported products over equivalent domestically-produced products, businesses persist in corporate governance activities that transfer U.S. jobs to lowwage countries as the simplest way to satisfy stockholder demands to achieve higher stock prices, and political leaders are all too often turning a blind eye to calls for protection domestic industries against invasion by foreign competitors. One thing is for sure - the U.S. trade balance will continue its meteoric trajectory, having surpassed the one-half trillion dollar mark - on its way to $\$ 1,000,000,000,000,000$. Hopefully the near-term future will see a populist movement by U.S. citizens whose reading of the international trade tea leaves will produce a demand for balanced trade with a voice that is stronger than those of the late twentieth century.

\section{BIBLIOGRAPHY}

1. Czinkota, Michael R., Ilkka A. Ronkainen, and Michael H. Moffet, International Business: Update 2000, New York: Dryden Press, 2000.

2. Buckley, Peter J. and Mark C. Casson, "Models of the Multinational Enterprise", Journal of International Business Studies, First Quarter 1998, pp. 21 - 44.

3. Gabberty, James, "Revving the Innovation Engine in China, Japan, and the U.S.", Journal of Innovation: Management, Policy \& Practice, Volume 6, Issue 1, April 2004.

4. Gabberty, James \& Calloway, Linda Jo, "China's ICT: Progressing toward Maturity from a Global Perspective", Proceedings of the International Applied Business Research Conference, Edinburgh (2004).

${ }^{1}$ Tyson, Laura D’Andrea, “Don't Worry, China Isn't Following in Japan's Footsteps”, Economic Viewpoint appearing in Business Week: April 20, 1998.

${ }^{2}$ Cooper, James C. and Madigan, Kathleen, “All Quiet at the Fed, But the Trade Deficit Looms”, Business Week, September 4, 2000 , p. 35.

${ }^{3}$ PBS Television series airing April 3, 10, 172002 entitled "Commanding Heights: The Battle for the World Economy" from the book by Yergin, Daniel and Joseph Stanislaw, The Commanding Heights: The Battle Between Government and the Marketplace That is Remaking the Modern World, New York: Simon \& Schuster, 1998. 